\title{
Teaching the History of English to University Students: a Synergetic Approach
}

\author{
T. I. Dombrovan
}

\author{
English Grammar Department, Odessa I.I. Mechnikov National University, Ukraine \\ Corresponding author. E-mail: dombrovan@gen.ua
}

Paper received 05.12.17; Revised 08.12.17; Accepted for publication 10.12.17.

https://doi.org/10.31174/SEND-HS2017-147V25-03

\begin{abstract}
This article proposes an alternative to dominant methods of teaching the history of the English language to university students. It links studies of language history with a novel approach to language studies, i.e. synergetics. An introduction to some basic concepts of linguistic synergetics is provided. A synergetic approach to language studies focuses on principles and mechanisms of language change and development and employs the methodological integrity of philosophy, linguistics and synergetics. The main aim of diachronic linguosynergetics is seen in capturing language in a state of change, when the language system follows a non-linear path, through numerous fluctuations and dissipation leading out of chaos to order and stability.
\end{abstract}

Keywords: linguistic synergetics, language development, synergetic system, the English language, the history of the English language.

Introduction. The history of language has been one of the obligatory disciplines for those studying philology at universities. The paramount importance of this subject is beyond any argument, as it demonstrates diverse tendencies in the historical development of the language and helps to understand current changes within the language system. Moreover, it may help to foresee possible ways of development of a language system in future. To become a professional linguist, the student should possess a profound knowledge of the history of a language (s)he studies.

The history of the English language is a course intended for undergraduates. Its aim is to acquaint future philologists and teachers of English with theoretical problems of language evolution and change in general and of English in particular, as well as to help them develop skills at implementing the obtained theoretical knowledge into practical teaching of modern English grammar, vocabulary, spelling and pronunciation.

The history of the English language is rightly considered as a cultural subject within the view of all educated people, too. In the words of A.C. Baugh, the history of English is a story of cultures in contact during the past 1,500 years $[6,1]$. This subject clearly demonstrates that the history of a language is indispensably connected with the history of the country/countries using this language as a means of communication.

Today, English is a world language, i.e. a language used for international communication throughout the world. Its importance is based on several objective criteria, such as the geographic distribution of its speakers, the extent of its function load, the economic and/or political influence of Englishspeaking countries, etc.

The past decade has seen a great number of articles, books and encyclopedias on the English language development. On the whole, they establish principal changes of language units on the phonetic, lexical and/or syntactic levels of its organization. Many authors represent the history of English as a succession of changes occurred in the language starting from $449 \mathrm{AD}$ and until nowadays. However, little has been done to reveal the very mechanisms of language changes. To meet such a demand, we should employ to language studies the methodology of synergetics as a science of self-organization of complex systems.

The term synergetics (from Greek coherent action) was coined by the German physicist Hermann Haken in the mid1970 s to name a science of complexity, dealing with princi- ples of emergence, self-organization and self-regulation of complex systems of various ontology - either human-made (artificial) or natural (self-organized) [10].

Successful application of concepts and methods of the synergetic approach to the description of biological, physical, historic, social, and even economic phenomena has revealed similarity, if not universality, of principles of evolution of complex systems. As a result, synergetics has made it possible to launch a wide variety of interdisciplinary interrelationships, among them: mathematical physics, mathematical history, social government, neurosynergetics, meteorology, geodynamics, prognostics, to mention just a few. The new disciplines, in their turn, require specialists with a profound knowledge of complex systems methodology. Otherwise, as Cliff Hooker points out, people whose education does not include relevant competency in complex systems are excluded from science, policy and large scale business or find themselves increasingly dependent on those who have it [12, $6]$.

Nowadays, the necessity of integration of different sciences is obvious and most scholars agree that the future of science lies within interdisciplinary research of complex systems. In the words of G. Malinetsky, the $21^{\text {st }}$ century is bound to become a century of the re-establishment of holism and deep understanding of common problems [4, 42]. It is interdisciplinary orientation that helps scientists think globally, i.e. beyond the borders of particular disciplines.

Drastic changes are taking place in the conceptual network of man now with the emergence of a synergetic view of the world as evolutionary, non-linear and holistic. "The old paradigm is being broken by a conceptual shift from "being" to "becoming", from stability and equilibrium to instability and non-linear phase transitions, from order to chaos serving as a basis for innovative changes in complex systems" $[3,70]$.

The aim of this article is to advance a new multidisciplinary research approach - diachronic linguosynergetics, focusing on principles and mechanisms of language change and development, and employing methodological integrity of philosophy, linguistics and synergetics. In what follows we are going to consider the notion of a complex system; we will also demonstrate that language is a synergetic system, and will introduce the methodology of diachronic linguosynergetics as a new multidisciplinary research approach.

This paper is based on the idea that modern teaching should not be reduced to mere enumerating linguistic chang- 
es and/or listing historical events that caused the latter. Description must be accompanied by explanation and reasoning. The teacher is not only to show the final result of a certain process but should also make the student think why and how such and such result has become possible. Synergetics may supply linguists with new methodological instruments and the conceptual network for studies of language change and development, thus enabling them to reach a higher level of their professional competence.

Research methods. The interdisciplinary (synergetic) synthesis should be considered as the key methodological principle of the present research. The following methods were also used: comparison and quantitative analysis of linguistic facts, generalization and systematization of modern scientific resources on the issue of formation and development of language as a synergetic system.

Discussion. No one would object to the statement that language is a complex system. What, then, is to be understood by «complex systems»?

A naïve assumption is based on a description of a complex system as the one having numerous components connected to each other. However, this interpretation is insufficient for research purposes: "A modern definition is based on the concept of algebraic complexity" [11, 4], i.e. includes a sequence of data describing both the interconnected network and cooperativity of the system's elements and their complex behaviour.

Robert C. Bishop considers it more informative to characterize complex systems phenomenologically and lists the following most important features in these characterizations: 1) Many-body systems. Some systems exhibit complex behaviour with as few as three constituents, while others require large numbers of constituents; 2) Broken symmetry. Various kinds of symmetries, such as homogeneous arrangements in space, may exist before some parameter reaches a critical value, but not beyond; 3) Hierarchy. There are levels or nested structures that may be distinguished, often requiring different descriptions at the different levels (e.g., large-scale motions in fluids vs. small-scale fluctuations); 4) Irreversibility. Distinguishable hierarchies are usually indicators of or result from irreversible processes (e.g., diffusion, effusion); 5) Relations. System constituents are coupled to each other via some kinds of relation, so are not mere aggregates like sand grain piles; 6) Situatedness. The dynamics of the constituents usually depend upon the structures in which they are embedded as well as the environment and history of the system as a whole; 7) Integrity. Systems display an organic unity of function which is absent if one of the constituents or internal structures is absent or if relations among the structures and constituents are broken; 8) Integration. Various forms of structural/functional relations, such as feedback loops couple the components contributing crucially to maintaining system integrity; 9) Intricate behaviour. System behaviour lies somewhere between simple order and total disorder such that it is difficult to describe and does not merely exhibit randomly produced structures; 10) Stability. The organization and relational unity of the system is preserved under small perturbations and adaptive under moderate changes in its environment; and 11) Observer relativity. The complexity of systems depends on how we observe and describe them. Measures of and judgments about complexity are not independent of the observer and her choice of measurement apparatus [7, 111-112].

A complex system manifests its phenomenal richness; consequently, it demands new ways of scientific analysis, as well as a new framework of categories. Synergetics suggests the integrity of methods elaborated in various disciplines and a wider variety of models to represent complexity of organic and inorganic systems.

We argue that human language is a complex synergetic megasystem, which changes and develops in compliance with the universal principles of the complex system's behavior revealed within the theory of synergetics. A human language represents a hierarchically organised megasystem, in which all the components (elements, subsystems, parts etc.) are coherently linked at all structural levels. A degree of complexity of any system is determined not only by a great number of its components, but also by a wide range of links and interactions among the components within the system, as well as by their ability to establish new (e.g. paradigmatic, syntagmatic, etc.) relations with other components and to fit in the existing links. The system's complexity is closely connected with its flexibility and dynamism.

It is obvious that language is always dynamic and undergoes both outer and inner influence. The language megasystem consisting of hierarchically structured and interconnected systems and subsystems is only relatively stable. Precisely speaking, it is unevenly stable, for some parts of it can be in equilibrium at a given moment, while the other parts are not.

The language system is flexible and is open to changes. However, its subsystems change at a different rate. A history of the English language proves that phonetic processes are of highest dynamics, while grammatical structures tend to remain more or less stable over the time. This confirms the supposition that the rate of changes taking place at different hierarchic levels of the language mega-system is in inverse proportion to the "size" of a language component: the less the component is, the more it is subjected to changes, and vice versa.

By "size" is understood not so much the linear length of the given component but its structural organisation. Thus, a phoneme is the smallest unit of a language system and the building material for morphemes. Morphemes are the smallest meaningful units of language and the building material for lexemes. Morphemes are known to fall into root morphemes, prefixes, suffixes, infixes, endings. Lexemes are made up according to certain combinatory patterns of morphemes. Compound lexemes have a more complex structure. A unit of the syntactic level, i.e. a sentence, has a considerably more complex organisation, for a sentence is a unit of communication and denotes various situations of the outer world. The degree of potential mobility of language levels increases towards structural simplicity of a language unit.

In terms of synergetics, language is a dynamic megasystem consisting of hierarchically organised levels differing from each other in rates (tempos) of changes that take place in their subsystems, - so to speak, "differently rated tempoworlds".

The term "tempo-world" was coined by S. Kurdyumov who defined it as a world the main characteristic of which is the same tempo of development of all its constituent complex structures [2, 195].

From the viewpoint of tempos of their change, language levels and their subsystems are characterized by different tempo-worlds and, consequently, they manifest various degrees of sensitivity and /or resistance to extra-linguistic factors that may lead the system out of equilibrium and final- 
ly bring about qualitative changes of either certain components or the whole system. To put it differently, parts of a mega-system differ in tempos of changes, which produces heterogeneity of co-evolutionary processes.

To retain its activity and functionality, a system should be not only dynamic but also flexible, i.e. a system must be able to adjust to changeable outer conditions, to alter its inner structure and behaviour, to select new options for a harmonised existence in the environment.

Dynamism, flexibility, adaptability of a given system, as well as a complicated variety of links among the system's components make up the notion of complexity.

Some scholars, and S. Kurdyumov in particular, in studying the phenomenon of complexity distinguish between the following two types: 1) disorganised (or chaotic) complexity, and 2) organised complexity. The first type is represented by a great number of parts (subsystems), interacting with each other chaotically. That is why disorganised complexity can be described within the theory of probability and statistical methods. By contrast, organised complexity is the type of complexity founded on determined, interdependent relationships among parts (subsystems) of the whole system.

It is obvious that at various moments of their existence evolving systems may be characterized by this or that type of complexity, depending upon the stage of the development of the given system. At the starting point, there is certain disorganisation in the state of instability of any system. The closer the system is towards a harmonised and stable state, the lesser the degree of chaos is. The system is organised by its control parameters leading it to an attractor, i.e. a new state of equilibrium. This means that at the stage of stability one type of complexity (the disorganised one) is ousted by the other (the so-called organised type complexity), and the whole system is able to exist and perform its functions in this new state until the environment allows it. When and if the outer conditions change, the system - which is always seeking self-preservation - will be looking for new means and forms of adaptation. This is why the stage of organised complexity may change into the stage of disorganised complexity: the system is always after new forms of existence. The process of changes aiming at adaptation to the altered environment starts anew.

Besides being dynamic and adaptive, a complex system must be open. «Openness» should be understood in the functional aspect, i.e. as the ability of the system to interact with other systems of the world, whatever their nature is. This interaction may include information exchange, energy exchange and / or substance exchange. Everything in the world is closely connected with one another; things and phenomena may be seen as separate only at a certain stage of the scientific study and for certain research reasons, because all that exists is integrated into the common network of interactions and interlinks.

The open character of language manifests itself in reflecting the social, economic, political and cultural life of the society, as well as the scientific and technological advances of the time. Besides reflecting, language transmits the new notions by saving them in its lexical depository. Language contacts, as a rule, result in various lexical borrowings. Nowadays, mass media and the global net have considerably accelerated the information exchange. Under the conditions of multinational society and global migrations of the population, language cannot but change, though only to a certain degree, for any system, including language, seeks self- preservation. To retain its form and functioning, the system may only allow insignificant fluctuations, i.e. such deviations in the dynamics of its components that do not lead to any disorder or chaos but preserve the subordination of the system's components.

In case of significant fluctuations, a part of a system or the whole system may lose equilibrium and enter the state of chaos and instability, which usually leads to a qualitatively new behaviour of the system and, as a result, to a new state of the system. The so-called order parameters function as synchronisers of the behaviour of the system's components. Order parameters are certain constants of the system determining the coordinates and the configuration of states of the system at a given moment or period of time and providing the system's ability to function.

In language, the role of order parameters is performed by various grammatical categories. In the course of time and as a result of the system's openness, the nomenclature of order parameters may change (compare, for instance, the parameter of word order in Old English to that of in Modern English).

The definition of language as a synergetic system should be supplemented with one more notion - the notion of nonlinearity.

Non-linearity as a mathematical notion stands for a certain type of mathematical equations that may have several absolutely different solutions. Non-linearity of a language system is revealed in dependency of features and functions of the system on behaviour of each of its component. The notion of linearity is probably applicable if we want to denote the order of language elements in a speech chain.

Summing up, human language can be defined as a complex synergetic megasystem, which changes and develops in compliance with the universal principles of the complex system's behaviour revealed within the theory of synergetics. Synergetic systems are multi-component systems characterized by complex behaviour of their parts and sub-systems. From the perspective of the synergetic approach, human language is considered an open, dynamic, non-linear, selforganizing system with all its hierarchical subsystems and elements coherently interconnected and controlled by governing parameters.

That the language system has features of a synergetic system (openness, complexity, non-linearity, etc.) calls for certain reconsideration of the notion of system and finally raises the question of the system's borders.

In philosophy, a system is usually defined as a set of components closely interconnected with one another. Any system is seen as a certain whole, representing a unity of its parts. The philosophical definition of a system has determined the conventional definition of a language system as a large coherent system including many subsystems connected with one another and united into the whole. Conventional definitions of a language system, though slightly different, have much in common because they are grounded on the following four main concepts, namely - unity, elements, structure and functions.

A synergetic view of a system allows including new senses into the notion of a system. It seems insufficient to imagine a system as a certain isolated set of components. The new definition of a system should include instability, openness, non-linearity, co-operation and co-evolution of its parts. These are the notions which should be introduced to students studying the history of language. Employing synergetic 
methodology can not only help to represent language development from a new angle but also to influence their view of the world as dynamic and ever changing.

Linguistic synergetics is a new stage in the investigation of language as an open self-regulating system. It offers new ways of describing the conventional object of analysis by using another meta-language and tools, and leads the science of language to a cross-disciplinary orbit.

The main task of linguistic synergetics is to reveal, describe and explain the mechanism of the inner dynamic structure of a language using research principles of synergetics as a paradigm of complexity. Diachronic synergetics, in particular, aims at modelling and interpretation of phaseshifts of the system, as well as at projecting possible variants of its change depending upon many-directional bifurcations and a variety of potential attractors. The main idea of diachronic synergetics lies within multi-directional non-linear evolution of language system. The concept of non-linearity is the most essential one for language development. The main aim of diachronic linguosynergetics is seen in capturing language in a state of change, when the language system follows a non-linear path, through numerous fluctuations and dissipation leading out of chaos to order and stability.

A close examination of historical changes in English within different language levels indicates that language never changes chaotically but has an underlying order based on the so-called space of states (a synergetic term), which provides directed chainlike mode of micro- and macro changes without positional skipping and contributes to preserving functional capability of the given system.

Our research [1] has proved that like any synergetic system, language has its own space of states, represented by the main morphological (topological) types of organization (agglutinating, analytic, inflectional, polysynthetic or incorporating, and isolating, or root). We suggest that under certain conditions any language is able to move along this space, changing its grammatical structure. Moreover, the history of the English language provides evidence of it.

Modern English belongs to analytical languages. However, elements of the other morphological types can be found in English, as well. The use of inflections (work-s, work-ing, work-ed, work-er, work-ing-s etc.) reveals remnants of the synthetic type to which Old English belonged. The lexeme child-ren-'s in which grammatical categories are expressed separately (those of number and case) is a perfect example of agglutination. The dominant type of syntactic relations, i.e. adjunction, is but a common feature of the English sentence (e.g. Dad saw John sleep like a log last night), and is typical of isolating languages. Meaning its rather rigid word order, some scholars speak of Modern English as drawing closer to isolating languages.

What, then, can account for absence of typologically "ideal" or "clear" languages? Why is it possible within the grammatical system of any national language to come across typological relics of other kinds? How can we explain emergence (in a given language) of new features characteristic of other types of morphological classification of the world languages? The answer seems to lie in the existence of the space of states of the language system. The space of states of a language includes all possible morphological types above mentioned.

Let us consider a few linguistic facts from the history of

\section{English}

Traditionally, the history of the English language is divided into three periods: Old English, Middle English, and Modern English. Considered from the type of the grammatical organization and following B. Shaw's observations, these periods are also referred to as the period of full inflections (Old English), the period of levelled inflections (Middle English), and the period of lost inflections (Modern English).

Obviously, Old English was a synthetic language. Old English (OE) nouns, adjectives, numerals and most semantic classes of pronouns had an elaborate system of inflections to mark a variety of grammatical categories (e.g. case, number, and gender). Moreover, there existed a number of types of declension of OE nouns. OE adjectives had a twofold declension - strong and weak depending upon their syntactic position, degree of comparison and the noun with which they agreed. The two OE participles (the Present Participle and the Past Participle) had a weak and a strong declension each. OE possessive pronouns, interrogative, indefinite, negative and relative pronouns changed according to the strong type of declension of adjectives. Some other pronouns and ordinal numerals had inflections of a weak type of declension of adjectives. The grammatical category of number of OE personal pronouns included, besides singular and plural, the dual number. The OE verb had the grammatical categories of mood (the Indicative, the Imperative, and the Subjunctive), of tense (Present and Past), of number (Singular and Plural), of person $\left(1^{\text {st }}, 2^{\text {nd }}\right.$, and $\left.3^{\text {rd }}\right)$ and a rather complicated system of conjugation depending upon the verb class. All above mentioned is but a fragment of a complex morphological system of Old English. A high degree of cohesion between words in a sentence allowed the so-called free word-order in Old English.

A trigger for further changes in the morphological system of English is seen in the Scandinavian invasion of the British Isles in the late 9 c. Scandinavian dialects belonged to the North Germanic group of languages and had much in common with Old English. Many everyday words in Scandinavian dialects and Old English had cognate root morphemes, which made the communication easier. However, it was complicated by case endings which were different in the languages. Gradually, the inflections were levelled, reduced and lost, drawing English towards the analytical type of language organization.

For our research, we chose five versions of The Lord's Prayer belonging to chronologically different periods of the English language history, namely:

I. - XI c. (Old English: Matthew 6.9 ; West Saxon Copy), II. - 1380 (Middle English: Matthew 6.9; Wycliffe's translation),

III. - 1611 (Modern English: The King James Bible),

IV. - 1928 (Late Modern English: Book of Common Prayer),

V. - 1977 (New English Version, adopted by the Church of England).

Written at different time periods, the texts of the Bible are a perfect illustration of changes that took place in the English language during the millennium. Using J. Greenberg's methods of analysis of morphological typology of languages, we have calculated a synthetic index for each of the versions of the Prayer. The obtained data are given in the following table: 
Table 1. A historical dynamics of the synthetic index of English

\begin{tabular}{|c|c|c|c|c|}
\hline I & II & III & IV & V \\
\hline Old English & Middle English & Modern English & Late Modern English & New English \\
\hline 0,5 & 0,2 & 0,1 & 0,1 & 0,1 \\
\hline
\end{tabular}

As seen in Table 1, the highest index refers to version I, while version 2 has a bit lower index. The later versions have practically the same index value. The historical dynamics of the synthetic index of English may be represented graphically in the following way:

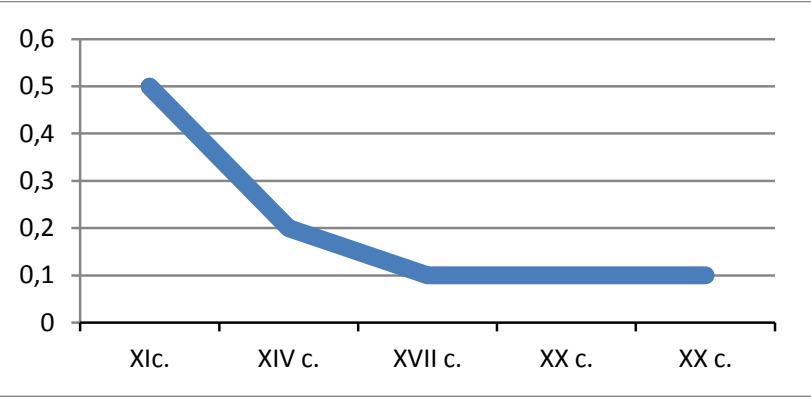

Fig.1 The historical dynamics of the synthetic index of English

The obtained data have reveal dynamism of the language system and have shown that a phase-shift took place in the structural organization of the system in the given period. A change of one parameter in a synergetic system triggered a chain reaction in the other parts of the system, which finally led the instable system to a structural re-organization.

To sum up, language as a synergetic system has a certain space of states (or phase space). Such characteristics of language as dynamism, non-linearity, adaptability, openness, etc., allow the language to balance between potential states and, under considerable influence of the environment, to tune into another state, i.e. to self-organize according to the altered control parameters of the system.

Conclusions. We live in a changing world. In modern society it is essential that methods of teaching should focus on formation of new skills for obtaining, analysis and critical comprehension of information by students. Modern education on the whole should be multidisciplinary in the sense that it is to acquaint students with recent findings, as well as with methodological changes, within both science and humanities.

Synergetics is regarded as a new methodology representing the outer world as the integrity of complex systems. A system is complex if it possesses a number of characteristics such as openness, dynamism, non-linearity, broken symmetry, hierarchy, irreversibility and so on.

A synergetic approach to language studies, which is advanced in the article, makes it possible to represent language as a synergetic system and to view the development of language from a new angle. It aims at understanding the main laws of language evolution - emergence of language, peculiarities of its non-linear development, coherent behaviour of its components and subsystems, the impact of external factors (including language contacts) on the language structure, etc.

Language must be considered in indissoluble connection with its speakers. Language history is closely related to the history of the people. Both language and the society change - through numerous fluctuations towards balanced states. Both follow a non-linear path, leading out of chaos to order and stability. Knowledge of mechanisms and principles of language change can help to foresee the variety of potential states of the analyzed complex system and to anticipate the behavior of the latter in the future. Under such circumstances, the value of synergetics on the whole and linguosynergetics in particular is hard to overestimate in modelling the historical changes of language and its society.

\section{REFERENCES}

1. Dombrovan T.I. (2014) Sinergeticheskaia model razvitiia angliiskogo iazyka [A Synergetic model of the English language development]. Odessa: KP OGT. [in Russian].

2. Kniazeva E.N., Kurdiumov S.P. (2011). Osnovaniia sinergetiki: Chelovek, konstruiruiushchii sebia i svoe budushchee [Fundamentals of synergetics: man, constructing himself and his future]. Moscow: Knizhnyi dom «LIBROKOM» [in Russian].

3. Kniazeva E.N., Kurdiumov S.P.(2011). Sinergetika: Nelineinost vremeni i landshafty koevoliutcii [Synergetics: Non-linearity of time and landscapes of co-evolution]. Moscow: KomKniga [in Russian].

4. Malinetckii G.G., Potapov A.B. (2011). Nelineinaia dinamika i khaos: Osnovnye poniatiia [Non-linear dynamics and chaos: Main notions]. Moscow: Knizhnyi dom «LIBROKOM». [in Russian].

5. Barber, Charles, Joan C.Beal and Philip A.Shaw (2009). The English Language: A Historical Introduction. Cambridge: Cambridge University Press.

6. Baugh, Albert C. and Thomas Cable (2006). A History of the English Language. L., Routledge.

7. Bishop, Robert C. Metaphysical and epistemological issues in

complex systems (2011). - In: Hooker, Cliff (ed.) Philosophy of Complex Systems [Handbook of the Philosophy of Science. Vol. 10]. Amsterdam; Boston, Heidelberg, London, etc.: Elsevier B.V.,106-136.

8. Blake, Norman F. (1996). A History of the English Language. Basingstoke \& London: MacMillan Press Ltd.

9. The Cambridge History of the English Language (1992-2001). Vols. 1-6. Cambridge: Cambridge University Press.

10. Haken, Hermann (1977). Synergetics. An Introduction. (Springer Series in Synergetics). Berlin: Springer-Verlag.

11. Haken, Hermann (2000). Information and Self-organization: A Macroscopic Approach to Complex Systems. (Springer Series in Synergetics). Berlin: Springer-Verlag.

12. Hooker, Cliff (2011). Introduction to Philosophy of Complex Systems: A. - In: Hooker, Cliff (ed.) Philosophy of Complex Systems [Handbook of the Philosophy of Science. Vol. 10]. Amsterdam; Boston, Heidelberg, London, etc.: Elsevier B.V., 3-90.

13. The Lord's Prayer in English [Electronic source].-Mode of access: http://www.ruf.rice.edu/ kemmer/Words04/history/paternoster.html

14. The Lord's Prayer (modern) [Electronic source]. - Mode of access: http://www.lords-prayer-words.com/

\section{Преподавание истории английского языка студентам университета: синергетический подход.}

\section{Т. И. Домброван}

Аннотация. В статье предлагается альтернативный метод преподавания истории английского языка университетским студентам, связывающий изучение истории языка с методологически новым, междисциплинарным подходом - синергетикой. Синергетический подход фокусируется на принципах и механизмах изменений в языке. Главная цель диахронической лингвосинергетики видится в изучении языковой системы в режиме неустойчивости и фазового перехода.

Ключевые слова: лингвосинергетика, развитие языка, синергетическая система, английский язк, история английского языка. 